\title{
MORPHOMETRIC ANALYSIS OF SHAPE OF SPECIMENS FROM THE NEOTYPE OF TABELLARIA FLOCCULOSA (BACILLARIOPHYCEAE) ${ }^{1}$
}

\author{
EDWARD THERIOT AND THEODORE B. LADEWSKI \\ Great Lakes Research Division, The University of Michigan, Ann Arbor, Michigan 48109
}

\begin{abstract}
A B S T R A C T
Shape variation of 67 specimens from the neotype slide of Tabellaria flocculosa was analyzed by computer-assisted morphometric techniques. Coefficients of a Legendre polynomial expansion of specimen shapes are shape descriptors used in principal component analysis (PCA). The first $\mathrm{PC}$ axis $\left(\mathrm{PC}_{1}\right)$ is highly correlated with valve length. Variation along $\mathrm{PC}_{1}$ is a combination of increase in width with a reduction in the distance between central and terminal inflations. The second axis $\left(\mathrm{PC}_{2}\right)$ is the major length-free component of shape variation. Variation in $\mathrm{PC}_{2}$ scores is related to the degree of constriction between the poles and the center. Shape variability increases as specimen length decreases. Three nonexclusive hypotheses can explain this: 1) different genetic entities are involved, 2) control of shape is strict in specimens longer than 35 $\mu \mathrm{m}$, but not for those less than $35 \mu \mathrm{m}, 3$ ) the pattern of variation reflects environmental variation during the period of development of the population.
\end{abstract}

MEMBERS OF THE diatom genus Tabellaria occur in abundance in a diversity of aquatic habitats. Its taxa are considered important indicators of lake acidity, a subject of topical concern (Flower and Battarbee, 1985). Although Tabellaria is not a particularly diverse diatom genus in terms of number of described taxa, its taxonomy is extremely difficult. There are as many different opinions on the diagnosis of taxa as there are investigators (Knudson, 1952, 1953a, b; Koppen, 1975; Flower and Battarbee, 1985). However, these authors agree that there are several basic taxonomic characters to be considered. Shape of the valve outline is perhaps foremost among these in both diagnostic importance and utility.

Shape in Tabellaria is highly variable, within and among taxa. Shape is to some degree dependent on valve length; this relationship confounds identification of taxa (Knudson, 1952). Until recently, diatomists lacked the necessary tools to quantitatively analyze shape of pennate diatoms, because they have few outline landmarks. Our laboratory has developed a method of shape quantification that relies on a minimum of landmarks (Stoermer and Ladewski, 1982). Applying this technique to the neotype of Tabellaria flocculosa (Roth) Kütz-

\footnotetext{
${ }^{1}$ Received for publication 19 April 1985; revision accepted 19 August 1985.

Neotype slide provided by Ms. P. A. Sims, British Museum (Natural History). We thank Dr. R. Kalinsky and an anonymous reviewer for constructive criticism of an earlier version of this article. Great Lakes Research Division Contribution no. 428 supported by N.S.F. Grant no. BSR-8218008.
}

ing, we discuss the morphological relationships between $T$. flocculosa and similar taxa, and evaluate the technique itself.

MATERIALS AND METHODS-Shape variation in neotype material of Tabellaria flocculosa (BM 22750) was analyzed by computer-assisted morphometric techniques. Outlines of 64 specimens deemed suitable for shape analysis were digitized (i.e., valves and free girdle bands with valvar planes lying parallel to the plane of focus). Example specimens are illustrated in Fig. 1-8. Three specimens were digitized twice to estimate measurement error in the digitization process, yielding a total of 67 shapes in the data set.

Each specimen outline shape was described using a Legendre polynomial expansion (Stoermer and Ladewski, 1982). Summarizing the method, the trans-apical distance is scaled to a standard length for all specimens, and the "half-width" (one half of the distance between margins measured perpendicular to the transapical axis) is measured at equal intervals along the trans-apical axis. A Legendre polynomial expansion of the half-width is calculated as a function of distance along the axis. The coefficients in the polynomial expansion are the shape descriptors used in this study and are labeled $\mathrm{C}_{0}, \mathrm{C}_{1}, \mathrm{C}_{2}$, etc. These descriptors are interpretable in terms familiar to diatom taxonomists. For example, $\mathrm{C}_{0}$ measures average width-to-length ratio, $\mathrm{C}_{1}$ measures "clavateness," $C_{2}$ measures "naviculoid-ness." Evennumbered descriptors $\left(\mathrm{C}_{0}, \mathrm{C}_{2}, \mathrm{C}_{4}\right.$, etc. $)$ measure symmetric aspects of shape, and odd-num- 


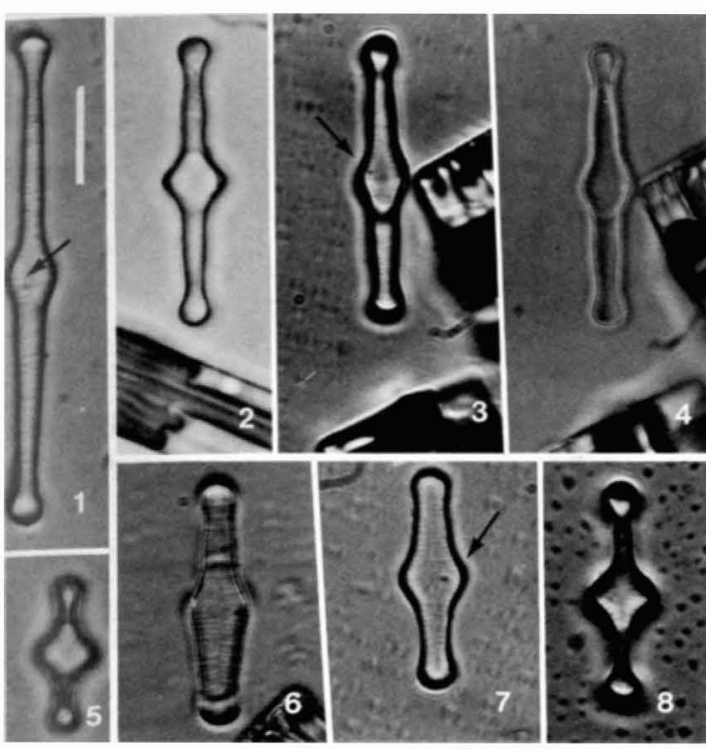

Fig. 1-8. Specimens from the neotype of Tabellaria flocculosa (BM 22750). Location of the labiate process is visible in a few specimens (arrows). Fig. 4 is low focus of the specimen in Fig. 3, illustrating detail of valve outline. Scale bar $=10 \mu \mathrm{m}$. These specimens are the outliers identified in Fig. 9 and illustrate the range of shape variation found in BM 22750.

bered descriptors measure asymmetric aspects of shape. Specimens are oriented so that the sign of $\mathrm{C}_{1}$ is positive, thus standardizing transverse assymmetry in all specimens.

Legendre descriptors $C_{0}$ through $C_{20}$ are used in multivariate analyses. Higher-order even terms $\mathrm{C}_{22}, \mathrm{C}_{24}, \mathrm{C}_{26}$, etc. are summed to create a descriptor labeled "UP 2 ." Higher order odd terms $\mathrm{C}_{21}, \mathrm{C}_{23}, \mathrm{C}_{25}$, etc. are summed to create descriptor UP $\mathrm{P}_{21}$. Use of these descriptors insures that the forms close at the ends (Stoermer and Ladewski, 1982). The median axis (line connecting mid-points of the chords between margins) can also be analyzed, but is ignored in this study because dorsal and ventral margins are nearly identical in all but a few specimens.

Principal component analysis (PCA) of the covariance matrix and cluster analysis using an average, unweighted clustering algorithm are used to analyze overall shape variation (Morrison, 1976; Sneath and Sokal, 1973). To test the stability of this covariance structure, the sample was split twice randomly into two subsets, one of 33 and one of 34 specimens, and each of the resultant data sets were reanalyzed with PCA.

The shape description technique is invertible. That is, the corresponding shape can be reconstructed from shape descriptors $C_{0}, C_{1}$,
TABLE 1. Principal component analysis of 67 outlines (64 specimens plus three duplicate outlines) of the neotype of Tabellaria flocculosa (Roth) Kützing (BM 22750)

\begin{tabular}{lrr}
\hline $\begin{array}{l}\text { Component } \\
\text { Cumulative } \\
\text { variance (\%) }\end{array}$ & $\mathrm{PC}_{1}$ & $\mathrm{PC}_{2}$ \\
\hline & 77 & 85 \\
\hline $\mathrm{C}_{0}$ & 0.39 & 0.64 \\
$\mathrm{C}_{1}$ & 0.02 & 0.04 \\
$\mathrm{C}_{2}$ & 0.30 & 0.38 \\
$\mathrm{C}_{3}$ & 0.02 & 0.09 \\
$\mathrm{C}_{4}$ & -0.45 & 0.36 \\
$\mathrm{C}_{5}$ & -0.03 & 0.00 \\
$\mathrm{C}_{6}$ & 0.69 & -0.18 \\
$\mathrm{C}_{7}$ & 0.00 & 0.04 \\
$\mathrm{C}_{8}$ & -0.21 & 0.20 \\
$\mathrm{C}_{9}$ & 0.00 & 0.01 \\
$\mathrm{C}_{10}$ & 0.00 & -0.23 \\
$\mathrm{C}_{11}$ & 0.02 & 0.00 \\
$\mathrm{C}_{12}$ & -0.09 & 0.29 \\
$\mathrm{C}_{13}$ & -0.01 & 0.02 \\
$\mathrm{C}_{14}$ & 0.02 & -0.17 \\
$\mathrm{C}_{15}$ & 0.00 & 0.01 \\
$\mathrm{C}_{16}$ & 0.05 & 0.11 \\
$\mathrm{C}_{17}$ & 0.00 & 0.00 \\
$\mathrm{C}_{18}$ & -0.05 & -0.05 \\
$\mathrm{C}_{19}$ & 0.00 & 0.00 \\
$\mathrm{C}_{20}$ & 0.06 & 0.06 \\
$\mathrm{UP}_{21}$ & 0.00 & -0.18 \\
$\mathrm{UP}_{22}$ & 0.00 & -0.14 \\
\hline & &
\end{tabular}

$\mathrm{C}_{2}$, etc. Invertibility also makes possible interpolation and extrapolation of outlines. This is done by interpolating or extrapolating descriptors along principal components and reconstructing outlines from the descriptors. Interpolated outlines show shape variability represented along a single principal component while extrapolated outlines can be used to test linearity of the major axis (as discussed below).

RESULTS-Girdle bands of $T$. flocculosa are closed, and each has a septa and pseudosepta (Koppen, 1975). No distinction can be made between the outlines of valves and girdle bands in our analysis apparently because these structures supply the girdle band with sufficient rigidity. Thus girdle band and valve outlines are pooled for the remainder of this paper.

Principal component analysis of the entire data set and each randomly selected subset revealed stable patterns of covariation in the first two PC axes, not greatly influenced by only a few specimens (Table 1). Common to all $\mathrm{PC}_{1}$ axes are moderate to high values for coefficients of even-numbered shape descriptors from $\mathrm{C}_{0}-\mathrm{C}_{8}$. Descriptors $\mathrm{C}_{0}, \mathrm{C}_{2}$ and $\mathrm{C}_{6}$ are always positive on $\mathrm{PC}_{1}$; descriptors $\mathrm{C}_{4}$ and $\mathrm{C}_{8}$, always negative. Odd descriptors had coefficients near zero. On $\mathrm{PC}_{2}$, even descriptors from 
TABLE 2. Principal component analysis of the neotype of Tabellaria flocculosa (Roth) Kützing (BM 22750). Separate analysis for each of two data sets: all specimens shorter than $35 \mu \mathrm{m}$ and all specimens longer than $35 \mu \mathrm{m}$

\begin{tabular}{|c|c|c|c|c|}
\hline \multirow{3}{*}{$\begin{array}{l}\text { Component } \\
\text { Cumulative } \\
\text { variance } \\
\text { (\%) }\end{array}$} & \multicolumn{2}{|c|}{$<35 \mu \mathrm{m}$} & \multicolumn{2}{|c|}{$>35 \mu \mathrm{m}$} \\
\hline & $\mathrm{PC}_{\mathrm{i}}$ & $\mathrm{PC}_{2}$ & $\mathrm{PC}_{1}$ & $\mathrm{PC}_{2}$ \\
\hline & 66 & 79 & 34 & 59 \\
\hline & \multicolumn{4}{|c|}{ Eigenvectors } \\
\hline $\mathrm{C}_{0}$ & -0.28 & 0.59 & 0.64 & 0.27 \\
\hline $\mathrm{C}_{1}$ & -0.01 & 0.04 & -0.03 & 0.08 \\
\hline $\mathrm{C}_{2}$ & -0.28 & 0.42 & 0.14 & 0.00 \\
\hline $\mathrm{C}_{3}$ & -0.02 & 0.09 & -0.07 & -0.02 \\
\hline $\mathrm{C}_{4}$ & 0.53 & 0.26 & -0.12 & 0.15 \\
\hline $\mathrm{C}_{5}$ & 0.02 & 0.00 & 0.08 & 0.00 \\
\hline $\mathrm{C}_{6}$ & -0.70 & -0.14 & 0.40 & 0.18 \\
\hline$C_{7}$ & 0.00 & 0.04 & -0.19 & 0.04 \\
\hline $\mathrm{C}_{8}$ & 0.25 & 0.18 & 0.04 & 0.16 \\
\hline $\mathrm{C}_{9}$ & -0.01 & 0.01 & 0.12 & 0.20 \\
\hline $\mathrm{C}_{10}$ & -0.04 & -0.28 & 0.13 & -0.04 \\
\hline$C_{11}$ & -0.01 & 0.00 & -0.13 & -0.21 \\
\hline $\mathrm{C}_{12}$ & 0.04 & 0.37 & -0.24 & 0.02 \\
\hline $\mathrm{C}_{13}$ & 0.00 & 0.02 & 0.03 & 0.13 \\
\hline $\mathrm{C}_{14}$ & 0.00 & -0.21 & -0.09 & -0.02 \\
\hline$C_{15}$ & 0.00 & 0.02 & 0.00 & -0.20 \\
\hline$C_{16}$ & 0.06 & 0.14 & 0.00 & 0.22 \\
\hline$C_{17}$ & 0.00 & 0.00 & -0.09 & 0.20 \\
\hline $\mathrm{C}_{18}$ & 0.07 & -0.08 & -0.06 & 0.05 \\
\hline $\mathrm{C}_{19}$ & 0.00 & 0.00 & -0.02 & -0.10 \\
\hline $\mathrm{C}_{20}$ & 0.06 & 0.07 & 0.07 & 0.26 \\
\hline $\mathrm{UP}_{21}$ & 0.00 & -0.19 & 0.28 & -0.02 \\
\hline $\mathrm{UP}_{22}$ & -0.01 & -0.14 & 0.37 & -0.72 \\
\hline
\end{tabular}

$\mathrm{C}_{0}-\mathrm{C}_{4}$ had high, positive coefficients. Coefficients of $\mathrm{C}_{6}$ were all negative and low to moderate in value; those of $\mathrm{C}_{8}$ were positive and moderate. However, $\mathrm{PC}_{3}$ does not exhibit this kind of stability, nor does it help segregate specimens (Fig. 9). Therefore it will be ignored in further analyses.

Specimen shapes along $\mathrm{PC}_{1}$ (Fig. 9), coefficients of shape descriptors (Table 1) and reconstructed outlines (Fig. 10) indicate that variation along $\mathrm{PC}_{1}$ is a combination of increase in valve width with a reduction in the distance between central and terminal inflations. $\mathrm{PC}_{1}$ is negatively correlated with valve length $(r=-0.87 ; P<0.01$; df $=65)$; however, the relationship is curvilinear (Fig. 11). Specimens longer than $35 \mu \mathrm{m}$ show little shape variation with change in length, but those less than $35 \mu \mathrm{m}$ change shape more rapidly relative to change in length.

The second axis $\left(\mathrm{PC}_{2}\right)$ is the major size-free component of shape variation. Variation along $\mathrm{PC}_{2}$ is related to the degree of constriction between the poles and valve center (Table 1; Fig. $9,10)$. The outlines of specimens at one extreme of $\mathrm{PC}_{2}$ are rectangular, but those at the other extreme have the three large inflations

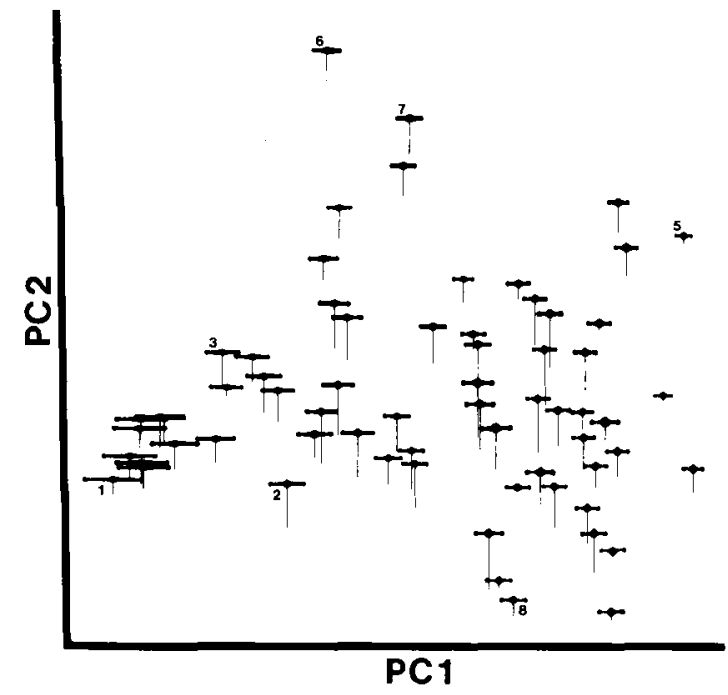

Fig. 9. Plot of specimens from the neotype of Tabellaria flocculosa (BM 22750) on the first three principal component axes (PC). Each symbol represents the digitized outline of one specimen. The numbered specimens correspond to those of Fig. 1-3, 5-8. The second principal component $\left(\mathrm{PC}_{2}\right)$ has been expanded about twice for the sake of clarity. Separation of specimens along $\mathrm{PC}_{3}$ is represented by the height of the vertical line below each symbol.

typical of Tabellaria. Specimens less than 35 $\mu \mathrm{m}$ in length are more variable in their $\mathrm{PC}_{2}$ scores than those greater than $35 \mu \mathrm{m}$ (Fig. 11).

Cluster analysis placed all specimens greater than $35 \mu \mathrm{m}$ in one cluster. The data were subdivided on the basis of length, and principal components were recalculated for each of the $<35 \mu \mathrm{m}$ and $>35 \mu \mathrm{m}$ specimen sets (Table 2 ). The first two PC axes of the short specimen set were similar to the first two of the complete set, describing a length-dependent relationship between width and the distance between central and terminal inflations, and length-free variation in the degree of constriction between the poles and center. However, the first two $\mathrm{PC}$ axes of the longer specimen set were quite dissimilar to the first two of the complete set. $\mathrm{PC}_{1}$ of longer specimens reflects variation in asymmetry about the long axis, unlike $\mathrm{PC}_{1}$ of all specimens or $\mathrm{PC}_{1}$ of only the short specimens.

DisCUSSION-Previous studies have emphasized the importance of shape for distinguishing Tabellaria taxa (Knudson, 1952, 1953a, b; Koppen, 1975). Knudson (1953b) recognized that variation in length has important consequences for shape in T. flocculosa: "Differences between frustules due merely to valve-length are not used to separate strains. ..." The length 

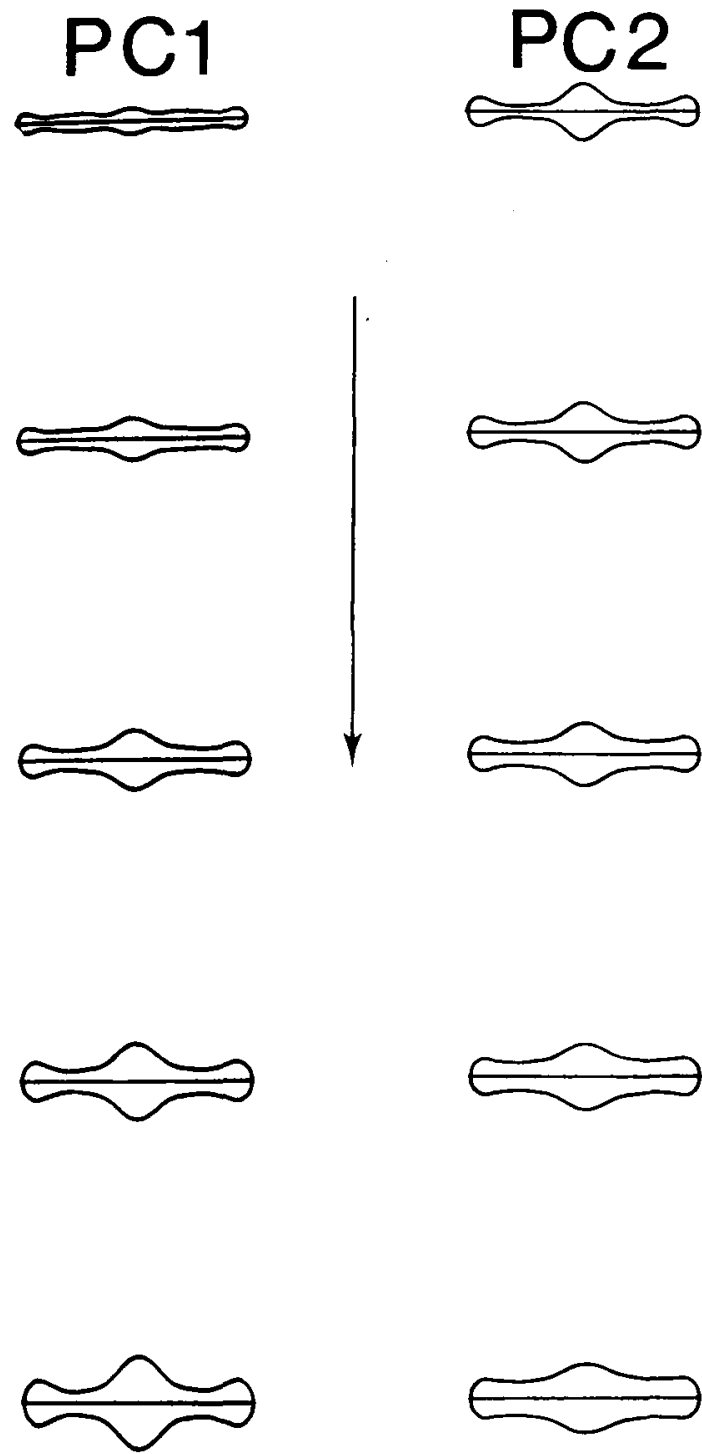

Fig. 10. Reconstruction of shape variation in the neotype of Tabellaria flocculosa (BM 22750) along the first and second principal components $\left(\mathrm{PC}_{1}\right.$ and $\left.\mathrm{PC}_{2}\right)$. From top to bottom, the shapes are respectively the shapes of hypothetical specimens having the minimum, $25 \%$ of the maximum, $50 \%$ of the maximum, $75 \%$ of the maximum and the maximum scores on each axis. In each reconstruction series, contributions of all other axes are held to zero. Thus, the middle reconstructed shape in each series is that of the overall "average" shape.

series of the neotype illustrated by Knudson (1952) corresponds well to variation along $\mathrm{PC}_{1}$. Knudson's (1952) figures appear to show the relationship between shape and length reported here, although she did not comment on it. Her illustrated specimens longer than $35 \mu \mathrm{m}$ exhibited strongly capitate ends, whereas those shorter than $35 \mu \mathrm{m}$ did not. Knudson (1952)
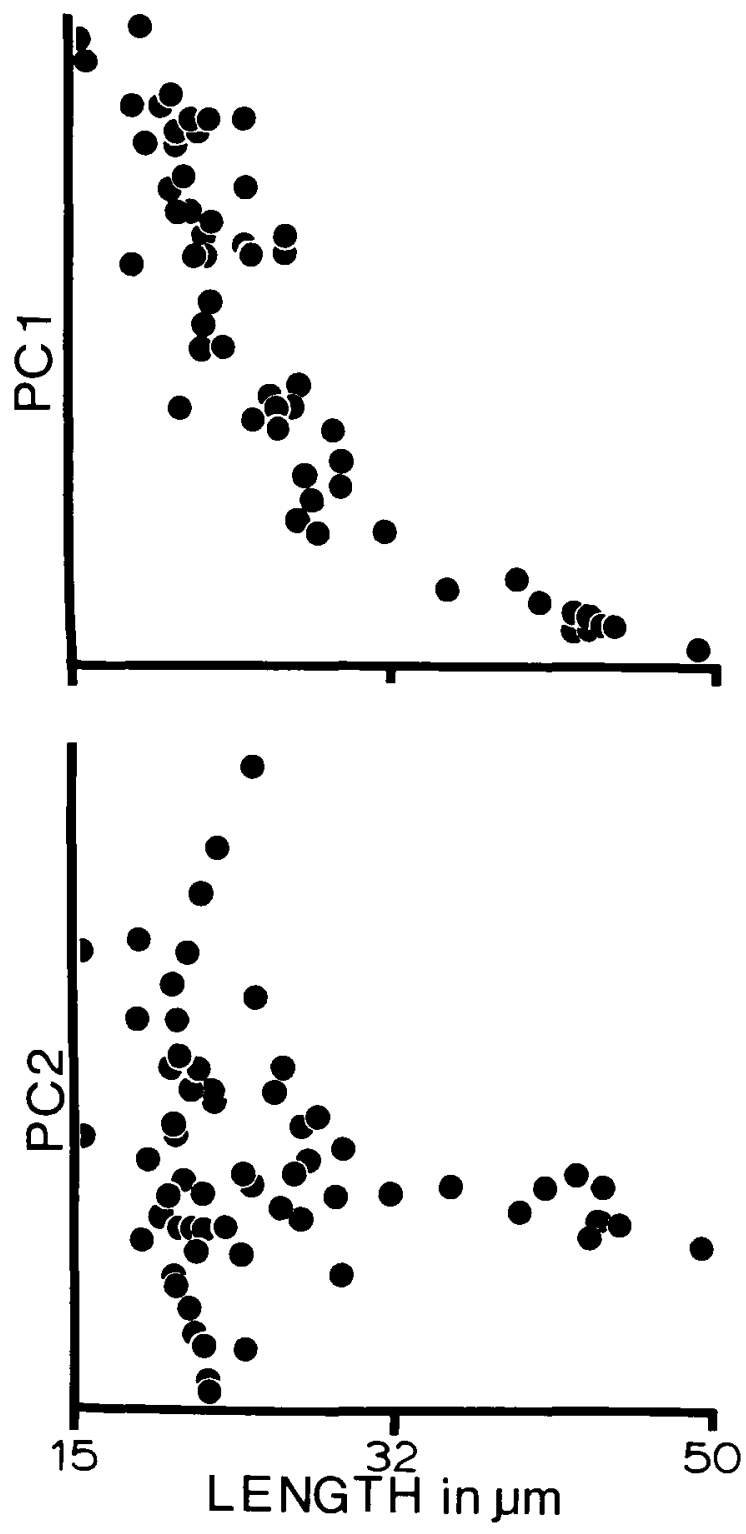

Fig. 11. A plot of first and second principal component $\left(\mathrm{PC}_{1}, \mathrm{PC}_{2}\right)$ scores versus valve length for the neotype of Tabellariaflocculosa (BM 22750). Each symbol represents at least one specimen.

also recognized considerable length-free variation within Tabellaria, particularly in the degree of prominence of the central and apical inflations. This description corresponds closely to variation along our $\mathrm{PC}_{2}$.

Shape variability in neotype specimens of $T$. flocculosa increases as specimen length decreases. Three hypotheses can explain this: 1) there are several different genetic entities in this sample, perhaps different taxa, 2) control of shape during valve formation is more precise 
at lengths in excess of $35 \mu \mathrm{m}, 3$ ) shape is affected by environmental conditions. These hypotheses are not mutually exclusive.

Regarding the first hypothesis, Knudson's (1952) opinion that the neotype contains one "morphological series" may need review. Koppen (1975) described a new variety and several informal groups and strains (sensu Koppen, 1975) of $T$. flocculosa, also stressing shape as a taxonomic character. Longer specimens of his group III have the morphology of longer specimens of the neotype, but shorter specimens (Koppen's fig. 30, 31) correspond to neotype specimens with high scores on $\mathrm{PC}_{2}$ (i.e., they are less constricted between the central and terminal inflations). Neotype specimens similar to his group IV series have low scores on $\mathrm{PC}_{2}$ (i.e., they are markedly constricted between the central and terminal inflations). However, this study does not find any apparent discontinuity in length-free variation; neotype specimens grade one into the other along $\mathrm{PC}_{2}$. Nevertheless, if Koppen's classification is correct then there may be two or more genetically distinct lineages represented by the neotype material. Knudson drew her inferences from a combination of cultured and field material but lacked electron microscopic observations. Koppen, however, depended entirely on field material and relied heavily on electron microscopic observations, considering girdle band structure to be an important taxonomic character. A combination of laboratory culture and ultrastructural approaches with quantitative analysis of shape variation is necessary to fully resolve this dispute.

The second possible hypothesis on the changes in quality and quantity of shape variation related to length variation contrasts with the commonly held viev; that pennate diatoms converge on a common morphology as they become smaller. Knudson (1952) reported that small valves of $T$. fenestrata are not distinctly capitate and so their outlines converge on those of T. flocculosa and T. quadriseptata Knudson. However, if Koppen's (1975) classification is correct, then some of the shorter forms in the neotype belong to different taxa. This might explain the observed increase in variation with decreasing length in the neotype.

The third hypothesis may have bearing on recent attempts to use diatom form variation to reconstruct paleolimnological events (Theriot and Stoermer, 1984) where environmental sources of variation can be identified. Knudson (1952, 1953a, b) recognized non-genetic variation in $T$. flocculosa, but correlations and cause-effect relationships between shape and particular environmental factors remain to be elucidated.
Knudson's (1952) conclusions on certain other Tabellaria taxa deserve reanalysis based on our observations. From culture evidence, she considered T. flocculosa var. compressa Woodhead et Tweed and T. fenestrata var. intermedia Grunow ex Van Heurck, respectively, as short and long extensions of the size series observed in the neotype of $T$. flocculosa. However, illustrated shorter specimens of Knudson's (1952) Blelham Tarn culture apparently do not show the marked constriction between the central and terminal inflations possessed by the shorter neotype specimens. Thus, one could interpret Knudson's Blelham Tarn culture as possibly representing a more nearly complete size range of $T$. flocculosa var. compressa, with the resultant implication that the two varieties are best distinguished at smaller sizes. Moreover, it is difficult to extrapolate shape variation in the neotype of $T$. flocculosa. This may be due to increased variability in shape as length decreases (assuming, as Knudson did, that only one taxon is represented on BM 22750) and/or the shape descriptor employed.

The major axis of shape variation in Legendre shape descriptor space is not straight. That is, $\mathrm{PC}_{1}$ of small specimens $(<35 \mu \mathrm{m})$ is not parallel to $\mathrm{PC}_{1}$ of large specimens $(>35$ $\mu \mathrm{m})$. Therefore it is not possible to accurately extrapolate the shape of large specimens from the $\mathrm{PC}_{1}$ of the small specimens, in contrast to Stoermer and Ladewski (1982) where the entire shape sequence of Gomphoneis herculeana (Ehrenb.) Cleve could be approximated from $\mathrm{PC}_{1}$ of either large or small specimens. The use of Legendre shape descriptors is especially appropriate for diatoms with gently, continuously curving outlines, such as Gomphoneis (Stoermer and Ladewski, 1982) and smaller Tabellaria specimens. Such specimen outlines are described well using only even-numbered descriptors up to $\mathrm{C}_{8}$. Outlines with long, straight sections, such as long Tabellaria specimens, require a larger number of shape descriptors because the Legendre series describes straight lines by interference of terms. While continued research is necessary to identify the most appropriate and/or general diatom shape descriptor, the good correspondence between Knudson's qualitative observations of 30 years ago and our PC axes indicates that Legendre polynomial expansion provides interpretable results for diatom taxonomy.

\section{LITERATURE CITED}

Flower, R. J., AND R. W. Battarbee. 1985. The morphology and biostratigraphy of Tabellaria quadriseptata (Bacillariophyceae) in acid waters and lake sed- 
iments in Galloway, southwest Scotland. Br. Phycol. J. 20: 69-79.

KNudson, B. M. 1952. The diatom genus Tabellaria. I. Taxonomy and morphology. Ann. Bot., N.S. 15: 421440.

-1953a. The diatom genus Tabellaria. II. Taxonomy and morphology of the plankton varieties. Ann. Bot., N.S. 17: 131-155.

. 1953b. The diatom genus Tabellaria. III. Problems of intra-specific taxonomy and evolution in $T$. flocculosa. Ann. Bot., N.S. 17: 598-609.

KOPPEN, J. D. 1975. A morphological and taxonomic consideration of Tabellaria (Bacillariophyceae) from the north-central U.S. J. Phycol. 11: 236-244.
MORRISON, D. F. 1976. Multivariate statistical methods, 2nd ed. McGraw-Hill, N.Y.

Sneath, P. H. A., AND R. R. Sokal. 1973. Numerical taxonomy. W. H. Freeman and Co., San Francisco.

STOERMER, E. F., AND T. B. LADEWSKI. 1982. Quantitative analysis of shape variation in type and modern populations of Gomphoneis herculeana. Beih. Nova Hedwigia 73: 347-386.

Theriot, E., AND E. F. Stoermer. 1984. Principal component analysis of character variation in Stephanodiscus niagarae Ehrenb.: morphological variation related to lake trophic status. In D. G. Mann [ed.], Proc. 7th Intl. Diatom Symp., Philadelphia, 22-27 August 1982, pp. 97-111. Otto Koeltz, Koenigstein. 